Cite this: RSC Adv., 2014, 4, 10240

Received 20th November 2013 Accepted 30th January 2014

DOI: $10.1039 / c 3 r a 46880 a$

www.rsc.org/advances

\section{Computational study of the working mechanism and rate acceleration of overcrowded alkene-based light-driven rotary molecular motors $\uparrow$}

\begin{abstract}
Changfeng Fang, Baswanth Oruganti and Bo Durbeej*
In recent years, much progress has been made in the design, synthesis and operation of light-driven rotary molecular motors based on chiral overcrowded alkenes. Through consecutive cis-trans photoisomerization and thermal helix inversion steps, where the latter dictate the overall rate of rotation, these motors achieve a full $360^{\circ}$ unidirectional rotation around the carbon-carbon double bond connecting the two (rotator and stator) alkene halves. In this work, we report quantum chemical calculations indicating that a particularly fast-rotating overcrowded alkene-based motor capable of reaching the $\mathrm{MHz}$ regime, can be made to rotate even faster by the substitution of a rotator methyl group with a methoxy group. Specifically, using density functional theory methods that reproduce the rate-limiting $\sim 35 \mathrm{~kJ} \mathrm{~mol}^{-1}$ thermal free-energy barriers shown by the methyl-bearing motor with errors of $\sim 5 \mathrm{~kJ} \mathrm{~mol}^{-1}$ only, it is predicted that this substitution reduces these barriers by a significant $15-20 \mathrm{~kJ}$ $\mathrm{mol}^{-1}$. This prediction is preceded by a series of benchmark calculations for assessing how well density functional theory methods account for available experimental data (crystallographic, UV-vis absorption, thermodynamic) on the rotary cycles of overcrowded alkenes, and a detailed examination of the thermal and photochemical reaction mechanisms of the original motor of this type.
\end{abstract}

\section{Introduction}

The construction and operation of motors of molecular dimensions that can execute useful functions is a formidable challenge and cornerstone activity in nanotechnology. ${ }^{1-3}$ Molecular motors are molecules that can perform work by absorbing external energy and converting the energy to directed (i.e., non-Brownian) mechanical motion such as rotation or translation. ${ }^{\mathbf{4 - 1 0}}$ Motors that produce unidirectional rotary motion are referred to as rotary molecular motors (or molecular rotors). Besides being able to control the direction (clockwise or counterclockwise) of rotation, such systems are characterized by their ability to rotate a full $360^{\circ}$ and to repeat the rotation for a large number of cycles through consumption of energy.

While Nature's biological machinery contains a number of complex protein assemblies that convert the energy stored in chemical bonds into directed rotary motion, ${ }^{11}$ such as ATP synthase, ${ }^{12}$ the first synthetic unidirectional rotary molecular motors were developed by Kelly ${ }^{\mathbf{1 3}}$ and Feringa ${ }^{\mathbf{1 4 , 1 5}}$ and their coworkers in the late nineties. Upon uptake of chemical and light energy, respectively, these systems produce motion consisting of rotation around a covalent bond: the former motor around a

Division of Computational Physics, IFM, Linköping University, SE-581 83 Linköping, Sweden.E-mail: bodur@ifm.liu.se

$\dagger$ Electronic supplementary information (ESI) available: Cartesian coordinates for stationary points, Tables S1-S6, and Fig. S1 and S2. See DOI: 10.1039/c3ra46880a carbon-carbon single bond in a triptycene derivative ${ }^{13}$ and the latter around a carbon-carbon double bond in a sterically overcrowded alkene. ${ }^{15}$ For both motors, chirality is an essential feature for the unidirectional rotary motion.

Especially the light-driven design by Feringa has inspired a wealth of subsequent experimental research., ${ }^{6,16-27}$ The original biphenanthrylidene motor, ${ }^{15}$ shown in Scheme 1 and denoted $\mathbf{1}$, features two identical halves connected by a central carboncarbon double bond. The configuration at the methyl-bearing stereogenic center is $(R)$ for both halves. $P$ denotes the righthanded helicity in each half of the motor, whereas $M$ (used later)

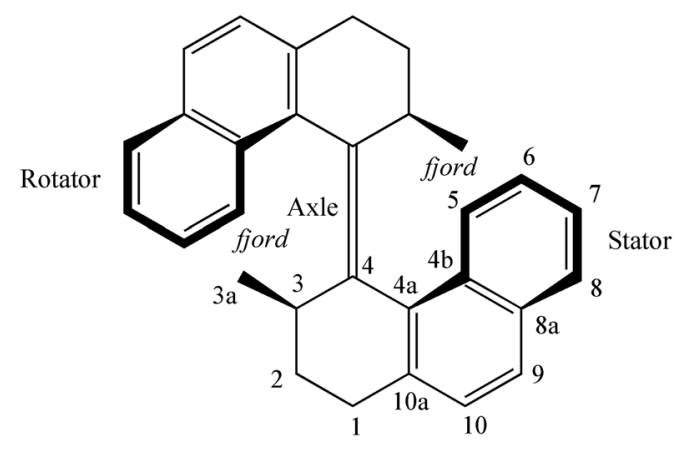

Scheme 1 Chemical structure and atom numbering of Feringa's firstgeneration $\quad\left(3 R, 3^{\prime} R\right)-(P, P)$-trans-1, $1^{\prime}, 2,2^{\prime}, 3,3^{\prime}, 4,4^{\prime}$-octahydro-3, $3^{\prime}$ dimethyl-4, $4^{\prime}$ - biphenanthrylidene rotary molecular motor 1 . 
denotes left-handed helicity. The upper motor moiety is taken as the "rotator" that can rotate around the double-bond axle, whereas the lower "stator" moiety can be immobilized on a surface. ${ }^{28-31}$

Each $360^{\circ}$ rotation achieved by 1 involves four discrete steps activated by UV light or a change in temperature of the system. ${ }^{15}$ The overall process can be described as follows (Fig. 1). ${ }^{15,22}$ In the first step, irradiation of the $(P, P)$-trans-1 isomer with UV light $(\lambda \geq 280 \mathrm{~nm})$ triggers a trans $\rightarrow$ cis photoisomerization around the central carbon-carbon double bond to produce the $(M, M)$-cis-2 isomer. This reaction occurs concomitantly with $(P, P) \rightarrow(M, M)$ inversion of the helicities of the two motor halves, and a change in orientation of the methyl substituents carried by the two stereogenic centers from favorable axial in $(P, P)$-trans-1 to strained equatorial in $(M, M)$-cis-2.

In $(M, M)$-cis-2, further isomerization continuing in the same direction as the initial trans $\rightarrow$ cis isomerization is prevented by steric hindrance. However, if the temperature is high enough, this hindrance can be overcome in an energetically downhill thermal $(M, M) \rightarrow(P, P)$ helix inversion process, in which the methyl groups regain their preferred axial orientation. This process constitutes the second step of the rotary cycle, produces the $(P, P)$-cis-2 isomer, and completes the first $180^{\circ}$ of the rotation.

In the third step, irradiation of $(P, P)$-cis-2 with UV light $(\lambda \geq$ $280 \mathrm{~nm}$ ) triggers a cis $\rightarrow$ trans photoisomerization that generates the $(M, M)$-trans-1 isomer, in which the methyl groups once more are forced to adopt a strained equatorial orientation. In further analogy with the first step, this reaction again changes the helicities of the motor halves from $(P, P)$ to $(M, M)$. Because of the preceding thermal step, the cis $\rightarrow$ trans photoisomerization can only proceed in the same direction as the initial trans $\rightarrow$ cis photoisomerization. Thus, these two photoisomerizations occur in a unidirectional fashion and produce truly rotary motion.

The fourth step, finally, is analogous to the second step in that it entails a spontaneous thermal $(M, M) \rightarrow(P, P)$ helix inversion and restores the preferred axial orientation for the

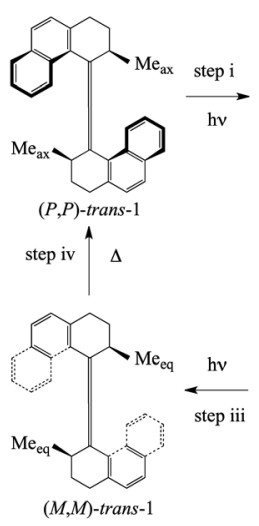

(a)
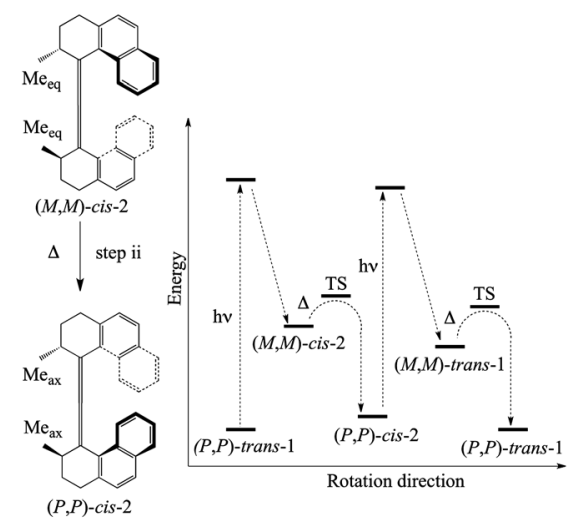

(b)
Fig. 1 (a) Rotary cycle of motor 1. (b) Energy profile of the rotary cycle. Adapted from M. M. Pollard, M. Klok, D. Pijper and B. L. Feringa, Rate Acceleration of Light-Driven Rotary Molecular Motors, Adv. Funct. Mater., 2007, 17, 718-729, with permission from John Wiley and Sons. methyl substituents. This step returns the system to the initial $(P, P)$-trans-1 state, thus completing the full $360^{\circ}$ rotation and allowing for a new cycle to begin.

As is clear from the foregoing dissection, the rotary cycle of 1 proceeds through sequential photochemical and thermal steps. The unidirectionality of the two photoisomerizations relies on the steric hindrance that the methyl substituents at the stereogenic centers introduce in the so-called fjord regions (see Scheme 1), and on the exergonicity of the thermal helix inversion steps, which effectively block back rotations. ${ }^{15,22}$ Based on quantum chemical calculations, a similar ratchet-like mechanism was recently found to be in operation in a photosensory protein - Anabaena sensory rhodopsin - that naturally converts light energy into unidirectional rotary motion. ${ }^{32}$

From the viewpoint of future applications of synthetic rotary molecular motors, which may include rotation of objects much larger than the motors themselves ${ }^{33}$ and molecular transport, ${ }^{34}$ two key challenges are reaching high rates of rotation under ambient conditions ${ }^{22,35}$ and mounting the motors on surfaces. ${ }^{7,28-31}$ In the first of these respects, however, motor 1 is not an ideal system, because the rate-limiting thermal helix inversion steps are very slow for this molecule. ${ }^{22}$ A major experimental effort has therefore been invested in the development of second-generation overcrowded alkene-based rotary molecular motors capable of operating at higher rotational frequencies than 1.6,16-27 Indeed, by ingenious design and careful organic synthesis, it has been possible to lower the freeenergy barriers of the thermal steps to such an extent that $\mathrm{MHz}$ frequencies are now realizable. ${ }^{25,27}$ One such motor, ${ }^{25}$ henceforth denoted 2, is shown in Scheme 2.

While it is clear that computational chemistry methods may fruitfully complement experimental endeavors to design fasterrotating molecular motors based on sterically overcrowded alkenes, no computational study in the existing literature seems to have been in-depth devoted to this particular topic, although a few other studies have used quantum chemical methods to put forward suggestions for improved light-driven rotary motors outside of the Feringa design. ${ }^{36-38}$ The present work is an attempt to help filling this important gap in the literature.

Among those other studies, Frutos and co-workers have recently proposed a motor that provides full $360^{\circ}$ unidirectional rotation from a chiral hydrogen-bond environment without the intermediacy of thermal steps. ${ }^{38}$ Our investigation is also related to a number of previous computational studies of Feringa-type motors that have rather focused on the photochemical steps of the rotary cycle, ${ }^{39-42}$ or on the ground-state conformational dynamics of these systems. ${ }^{43}$

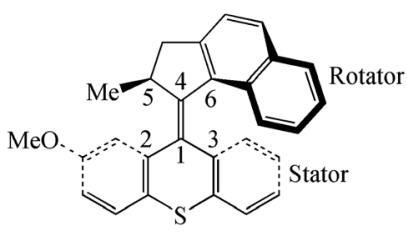

Motor 2

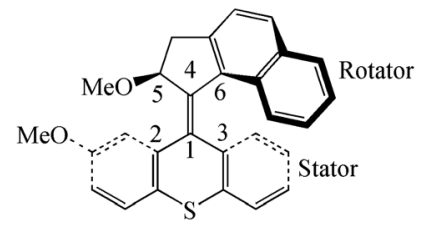

Motor 3
Scheme 2 Chemical structures of the trans isomers of motors 2 and 3. 
Specifically, this work reports quantum chemical calculations using density functional theory (DFT), including time-dependent density functional theory (TD-DFT) ${ }^{44-50}$ for the treatment of excited states, that illustrate the potential of such calculations to aid the development of faster-rotating overcrowded alkenebased molecular motors. First, we explore the rotary cycle of $\mathbf{1}$, including both photochemical and thermal steps, and find that a number of density functionals are able to demonstrate the unidirectionality of the two photoisomerizations, and to reproduce experimentally obtained structural, spectroscopic and thermodynamic data of the rotary cycle with reasonable accuracy. Furthermore, these calculations support experimental indications ${ }^{20}$ that the thermal helix inversion steps occur by a stepwise rather than concerted mechanism. Second, we consider the second-generation motor 2 , and compute free-energy barriers for the thermal steps that closely reproduce the corresponding experimental estimates, and are consistent with the observation that this motor is able to reach much higher rotational frequencies than $1 .^{25}$

Finally, having demonstrated the appropriateness of the computational methodology, we apply it to our own suggestion for a new second-generation motor (henceforth denoted 3 and also shown in Scheme 2) that is very similar to 2 , but whose thermal barriers, we reasoned, should be lower by the replacement of the C5 methyl group (in 2) with a methoxy group (in 3). Thereby, we find that the thermal barriers for $\mathbf{3}$ are indeed a sizable $15-20 \mathrm{~kJ} \mathrm{~mol}^{-1}$ lower, and are thus able to predict that this molecule may well surpass the $\mathrm{MHz}$ rotational frequencies achieved by motor $2 .{ }^{25}$

\section{Computational methods}

To explore the rotary cycle of $\mathbf{1}$, stationary points on the groundstate $\left(\mathrm{S}_{0}\right)$ potential energy surface (PES) corresponding to the light-absorbing $(P, P)$-trans-1 and $(P, P)$-cis-2 isomers were first located by performing geometry optimizations with the $\mathrm{B}^{2} \mathrm{LYP}^{51-53}$ global and $\omega \mathrm{B} 97 \mathrm{X}-\mathrm{D}^{54}$ long-range-corrected hybrid density functionals in combination with the double- $\zeta$ SVP (split valence plus polarization) basis set. ${ }^{55}$ While B3LYP is widely regarded to provide accurate molecular structures, the use of $\omega$ B97X-D is primarily motivated by it being a suitable method for much of the subsequent modeling, as further discussed below. Hence, $\omega$ B97X-D was employed also in this initial step of the modeling. In complementary calculations (see below), alternative density functionals were also considered, and the appropriateness of using $\omega$ B97X-D for ground-state geometry optimizations was assessed.

To account for the fact that part of the experimental characterization of $(P, P)$-trans- 1 and $(P, P)$-cis-2 was done in a hexane or methanol solution, ${ }^{14}$ and to assess the magnitude of solvent effects, the B3LYP and $\omega$ B97X-D optimizations were carried out both in the gas phase and using the integral equation formulation $^{56}$ of the polarizable continuum model (PCM) ${ }^{57}$ to describe the solvent. For the resulting geometries, frequency calculations were performed at the corresponding levels of theory to ensure that these structures are potential-energy minima, as well as to derive Gibbs free energies (at room temperature).
Starting from the ground-state structures of $(P, P)$-trans- 1 and $(P, P)$-cis-2, the photoisomerization paths in the lowest excited singlet state $\left(\mathrm{S}_{1}\right)$ toward the $(M, M)$-cis-2 and $(M, M)$-trans-1 isomers were computed in the following way, considering both gas phase and solution environments. First, TD-DFT singlepoint calculations using $\omega \mathrm{B} 97 \mathrm{X}-\mathrm{D} / \mathrm{SVP}$ were carried out to obtain the vertically excited Franck-Condon (FC) point of the respective path. These calculations were followed by TD-DFT geometry optimizations, enabled by the availability of analytic TD-DFT gradients, ${ }^{58-61}$ at the same level of theory to model the subsequent relaxation from the FC points to excited-state minima henceforth denoted $(P, P)$-trans $-1 *$ and $(P, P)$-cis- $2^{*}$. This relaxation initiates the photoisomerizations at the $\mathrm{C} 4-\mathrm{C} 4^{\prime}$ double bond and defines a direction (clockwise or counterclockwise) for the rotary motion of 1 during its photocycle.

Starting from $(P, P)$-trans- $1^{*}$ and $(P, P)$-cis-2*, additional points along the photoisomerization paths were then obtained by performing a series of constrained TD-DFT optimizations, where for each optimization all other geometric parameters than the $\mathrm{C} 4 \mathrm{a}-\mathrm{C} 4-\mathrm{C} 4^{\prime}-\mathrm{C} 4^{\prime}$ a dihedral angle (henceforth denoted $\alpha$ ) were allowed to relax. The set of $\alpha$ values considered for these calculations cover, in steps of $10^{\circ}$, the full range $\left(-180^{\circ}\right.$ to $\left.180^{\circ}\right)$ of possible dihedral angles. Based on a comparison of the FC relaxation in the gas phase and in solution (discussed in detail below) and for computational expedience, all of the constrained TD-DFT optimizations were carried out in the gas phase.

Based on earlier computational studies of photoisomerizations of organic molecules, ${ }^{62-67}$ the decay processes from the excited state to the ground state that precede the formation of the photoproducts [i.e., the $(M, M)$-cis-2 and $(M, M)$-trans-1 isomers] are expected to be mediated by conical intersections at highly twisted geometries where the two states are degenerate. However, since, despite recent progress, ${ }^{68-72}$ conical intersections are yet to lend themselves easily to location by means of DFT methods and since the multi-reference $a b$ initio approaches best suited for such calculations (e.g., $\mathrm{CASSCF}^{73}$ ) remain too expensive for straightforward application to large conjugated systems, no attempt was made to demonstrate the occurrence of conical intersections along the current photoisomerization paths. Instead, the $(M, M)$ cis-2 and $(M, M)$-trans-1 isomers were located directly by starting ground-state $\omega \mathrm{B} 97 \mathrm{X}-\mathrm{D} / \mathrm{SVP}$ geometry optimizations at highly twisted $\left(-110^{\circ} \leq \alpha \leq-70^{\circ}\right.$ and $70^{\circ} \leq \alpha \leq 110^{\circ}$, respectively) structures along the photoisomerization paths.

Importantly, irrespective of which twisted starting point was used from the respective path, these optimizations produced a number of identical structures of both $(M, M)$-cis-2 and $(M, M)$ trans-1. Furthermore, starting ground-state geometry optimizations from less twisted excited-state structures invariably returned the system to the parent $(P, P)$-trans-1 and $(P, P)$-cis-2 isomers. Thereby, it could be ascertained that the computed photoisomerization paths do indeed connect the parent isomers to the $(M, M)$-cis-2 and $(M, M)$-trans-1 isomers, which is important in light of the fact that the photochemical reaction coordinate $(\alpha)$ in our approach is presumed rather than defined by minimum energy path calculations. ${ }^{74}$

As for modeling the photoisomerization steps of the rotary cycle with a long-range-corrected hybrid functional ( $\omega$ B97X-D), 
this choice is largely based on two findings. First, it has been reported that standard functionals like B3LYP may face problems in accounting for partial $\pi$-bond breaking during doublebond isomerization reactions. ${ }^{75}$ Second, it has been found that long-range-corrected hybrids, which in part have been designed to reduce well-known errors ${ }^{\mathbf{4 9}, 76}$ in TD-DFT excitation energies for states with appreciable charge-transfer character (by allowing the fraction of included exact exchange to vary with the interelectronic distance; between $22 \%$ at short range and $100 \%$ at long range for the case of $\omega \mathrm{B} 97 \mathrm{X}-\mathrm{D}),,^{54,77-81}$ also improve the TD-DFT description of photoisomerizations around carboncarbon double bonds in conjugated systems. ${ }^{\mathbf{8 2 , 8 3}}$ Specifically, studying the cis-trans photoisomerization of a retinal chromophore, Rostov et al. found that a number of long-range-corrected hybrids, including $\omega \mathrm{B} 97 \mathrm{X}-\mathrm{D}$, consistently produce more accurate excited-state PESs for this process than B3LYP. ${ }^{\mathbf{8 2 , 8 3}}$ Another advantage of using $\omega$ B97X-D for the present molecules is that this functional includes dispersion, ${ }^{54}$ accounted for in the form of empirical atom-atom dispersion corrections. ${ }^{\mathbf{8 4 , 8 5}}$

In addition to using $\omega$ B $97 \mathrm{X}-\mathrm{D}$, parts (the FC relaxation) of the calculations for the $S_{1}$ photoisomerization paths were also carried out with a set of complementary methods. This set included BP86, BLYP [pure density functionals based on the generalized gradient approximation (GGA)], ${ }^{51,86,87}$ B3LYP, PBE0 (global hybrid GGAs with 20 and $25 \%$ exact exchange, respectively), ${ }^{51-53,88}$ M06-2X (a global hybrid meta-GGA with 54\% exact exchange), ${ }^{89} \omega \mathrm{B} 97 \mathrm{X}$ (the long-range-corrected hybrid GGA from which $\omega$ B97X-D was developed), ${ }^{81}$ and the $a b$ initio configuration interaction singles (CIS) method. ${ }^{90}$

Having located stationary points on the $\mathrm{S}_{0}$ PES of 1 corresponding to the four $(P, P)$-trans-1, $(M, M)$-cis-2, $(P, P)$-cis-2 and $(M, M)$-trans-1 isomers, the kinetics of the two thermal helix inversion $(M, M)$-cis-2 $\rightarrow(P, P)$-cis-2 and $(M, M)$-trans- $1 \rightarrow(P, P)$ trans-1 steps were investigated by mapping regions of the $S_{0}$ PES encompassing both stepwise and concerted mechanisms. Specifically, continuing to use B3LYP and $\omega$ B97X-D in combination with the SVP basis set and examining the reactions in both the gas phase and in solution, this investigation involved location of transition structures and frequency and intrinsic reaction coordinate (IRC) calculations ${ }^{91}$ to verify that located transition structures do indeed mediate helix inversions.

Finally, as for the calculations on Feringa's second-generation rotary molecular motor 2 and our suggestion for a redesigned version 3 thereof, these were done with the same exact protocol as the calculations on motor $\mathbf{1}$ just described, but with the PCM settings modified to represent the dichloromethane solvent used in the experimental reference study. ${ }^{25}$

Except where otherwise noted, all calculations were performed with the Gaussian 09 suite of programs. ${ }^{92}$

\section{Results and discussion}

\subsection{The parent $(P, P)$-trans -1 and $(P, P)$-cis-2 isomers}

To investigate how well $\omega$ B97X-D compares with B3LYP for ground-state properties of $\mathbf{1}$ and to assess the magnitude of solvent effects, Table 1 lists key geometric parameters and relative free energies of the parent $(P, P)$-trans-1 and $(P, P)$-cis-2 isomers obtained with these methods in the gas phase and in hexane and methanol solvents. For the geometric parameters, which include the central $\mathrm{C} 4-\mathrm{C} 4{ }^{\prime}$ double bond, the $\alpha$ dihedral angle, and four other dihedrals that are also relevant for characterizing the rotary cycle, experimental data (obtained using $\mathrm{X}$-ray crystallography ${ }^{\mathbf{1 4}}$ ) are listed as well.

Starting with the comparison between the two functionals and focusing this analysis on the gas-phase results, which are affected by fewer computational factors than the PCM results, it should first be noted that such a comparison is particularly warranted since long-range-corrected functionals like $\omega$ B97X-D aimed especially at yielding accurate TD-DFT excitation energies have sometimes been found to accomplish this goal only at the expense of accuracy in ground-state properties. ${ }^{93}$ In this light, it is interesting to note that there is no substantial difference between the $\omega$ B97X-D and B3LYP geometries of $(P, P)$ trans-1 and $(P, P)$-cis-2, as indicated by the corresponding gasphase parameters in Table 1 [and made clear by a comparison of the full geometries included in part 10 of the ESI $\dagger$ ]. Furthermore, it is pleasing that both functionals reproduce the crystallographic data of ref. 14 quite well, with the calculated $\alpha$ and $\beta$ dihedrals deviating by at most $\sim 7^{\circ}$ from these data.

One result on which the functionals differ, however, is the relative free energies of the two isomers: $\omega$ B97X-D predicts $(P, P)$ cis-2 to be $3.9 \mathrm{~kJ} \mathrm{~mol}^{-1}$ more stable than $(P, P)$-trans-1 in the gas phase, whereas B3LYP conversely predicts $(P, P)$-cis-2 to be $10.6 \mathrm{~kJ} \mathrm{~mol}^{-1}$ less stable. Although smaller than the computational accuracy needed for the conclusions drawn in this work, this effect warrants further examination of how sensitive calculated free energies of the ground-state stationary points of $\mathbf{1}$ are to the choice of functional and basis set (beyond SVP). The results of such an investigation are summarized and discussed in the ESI (Tables S1 and S2 $\dagger$ ). From this, it can be inferred that these energies are not very sensitive to the level of theory, and argued that the fact that $\omega$ B97X-D and B3LYP slightly differ in some respects, yet without ambiguity support the same overall conclusions, helps solidifying these conclusions.

As for solvent effects, finally, the selected results in Table 1 are a clear reflection of what can be deduced more thoroughly from part 10 of the ESI: $\dagger$ the gas-phase geometries of the various isomers of $\mathbf{1}$ are very similar to the ones obtained by performing geometry optimizations in an experimentally relevant ${ }^{14}$ solvent. This is likely a consequence of $\mathbf{1}$ being a neutral species. The solvent exerts a somewhat more noticeable effect on the calculated free energies, but not to an extent that its presence appears to be of qualitative importance. For $(P, P)$-trans-1 and $(P, P)$-cis-2, the solvent stabilizes the latter more than the former, and increasingly so when going from hexane (5.6-7.4 $\mathrm{kJ} \mathrm{mol}^{-1}$ ) to methanol (12.9-14.2 $\left.\mathrm{kJ} \mathrm{mol}^{-1}\right)$.

\subsection{Absorption maxima and photochemical steps}

The rotary motion of $\mathbf{1}$ is powered by UV-vis absorption at $\lambda \geq$ $280 \mathrm{~nm} \cdot{ }^{\mathbf{1 4 , 1 5}}$ As part of the tests of the computational methodology, it is then of interest to assess how well TD-DFT using $\omega$ B97X-D can reproduce the experimental absorption maxima of $(P, P)$-trans-1 (at $327 \mathrm{~nm} / 3.80 \mathrm{eV}$ ) and $(P, P)$-cis-2 (at $302 \mathrm{~nm} / 4.11$ 
Table $1 \omega$ B97X-D and B3LYP ground-state geometric parameters and relative free energies $(\Delta G)$ of the $(P, P)$-trans-1 and $(P, P)$-cis-2 isomers of motor 1 in the gas phase and in solution ${ }^{a}$

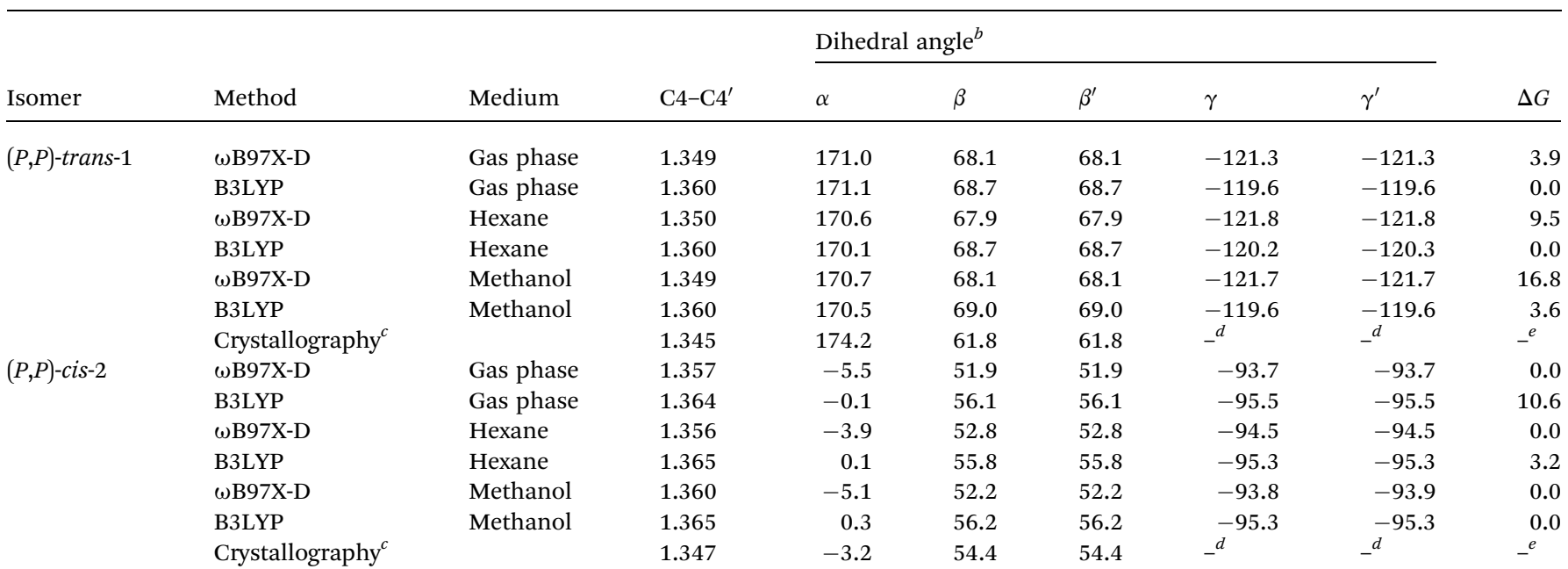

${ }^{a}$ Bond lengths in $\AA$, dihedral angles in degrees, and energies in $\mathrm{kJ} \mathrm{mol}^{-1}{ }^{b}$ With reference to Scheme 1 , dihedral angles are defined as follows: $\alpha=$ $\mathrm{C} 4 \mathrm{a}-\mathrm{C} 4-\mathrm{C} 4^{\prime}-\mathrm{C} 4^{\prime} \mathrm{a}, \beta=\mathrm{C} 4-\mathrm{C} 4^{\prime}-\mathrm{C} 4^{\prime} \mathrm{a}-\mathrm{C} 4^{\prime} \mathrm{b}, \beta^{\prime}=\mathrm{C} 4^{\prime}-\mathrm{C} 4-\mathrm{C} 4 \mathrm{a}-\mathrm{C} 4 \mathrm{~b}, \gamma=\mathrm{C} 4-\mathrm{C} 4^{\prime}-\mathrm{C} 3^{\prime}-\mathrm{C} 3^{\prime} \mathrm{a}$, and $\gamma^{\prime}=\mathrm{C} 4^{\prime}-\mathrm{C} 4-\mathrm{C} 3-\mathrm{C} 3 \mathrm{a}$. ${ }^{c}$ Experimental data from ref. 14 . ${ }^{d}$ Experimental data not given in ref. $14 .{ }^{e}$ Experimental data not available.

eV). ${ }^{14}$ This is done in Table 2 through calculation of vertical $\mathrm{S}_{0} \rightarrow \mathrm{S}_{1}$ excitation energies, carried out both in the gas phase and in the hexane and methanol solvents employed in the experiments. ${ }^{14}$ In addition, Table 2 also includes the corresponding adiabatic excitation energies obtained from TD-DFT/ $\omega$ B97X-D geometry optimizations, and details some of the structural changes associated with the ensuing relaxation from the FC points to the $(P, P)$-trans- $1^{*}$ and $(P, P)$-cis- $2^{*}$ minima.

As can be seen from Table 2, the $\omega$ B97X-D vertical excitation energies are in reasonable agreement with the experimental absorption maxima, and are not appreciably shifted between the different environments. In contrast to the experiments, however, these excitation energies do not yield a blue shift for the absorption of $(P, P)$-cis-2 relative to $(P, P)$-trans-1, but a red shift. A similar result has been reported in a previous computational study ${ }^{40}$ using the BH\&HLYP global hybrid functional (that incorporates $50 \%$ exact exchange) ${ }^{94}$ in the framework of TD-DFT, as well as in combination with a state-averaged variant of the spin-restricted ensemble-referenced Kohn-Sham method. ${ }^{95}$

One possible explanation for this discrepancy is that geometric relaxation effects weaken the (standard) assumption that experimental absorption maxima correspond to vertical transitions (the vertical approximation), because the calculated adiabatic excitation energies in Table 2 do yield a blue shift for $(P, P)$-cis-2 relative to $(P, P)$-trans-1. Another possibility is simply that the $\omega$ B97X-D vertical excitation energies are erroneous in this particular regard. Testing whether other methods would perform differently, Table 3 lists vertical and adiabatic excitation energies of the two isomers obtained with six alternative density functionals (BP86, BLYP, B3LYP, PBE0, M06-2X and $\omega \mathrm{B} 97 \mathrm{X})$ and CIS. Based on the $\omega \mathrm{B} 97 \mathrm{X}-\mathrm{D}$ results, these calculations were carried out in the gas phase. Interestingly, analogously to $\omega \mathrm{B} 97 \mathrm{X}-\mathrm{D}$, all of these methods yield a red shift for the absorption of $(P, P)$-cis-2 relative to $(P, P)$-trans-1 if vertical excitation energies are considered. As far as this test is concerned,

Table $2 \omega B$ 97X-D vertical (VEE) and adiabatic (AEE) $S_{0} \rightarrow S_{1}$ excitation energies of the $(P, P)$-trans-1 and $(P, P)$-cis-2 isomers of motor 1 in the gas phase and in solution, and associated changes in geometric parameters during the FC relaxation ${ }^{a}$

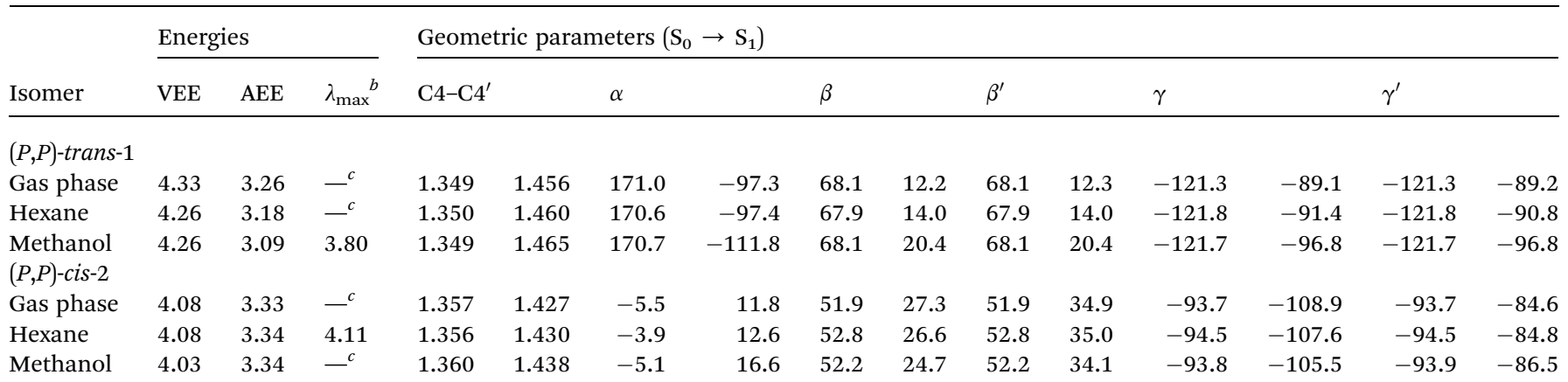

${ }^{a}$ Excitation energies in $\mathrm{eV}$, bond lengths in $\AA$, and dihedral angles in degrees. ${ }^{b}$ Experimental absorption maximum (in eV) from ref. 14 .

${ }^{c}$ Experimental data not available. 
then, there seems to be no obvious reason to use another functional than $\omega$ B97X-D for the photochemical modeling. Further support for this thesis comes from complementary calculations summarized in Table S3 of the ESI, $\uparrow$ whereby also the $a b$ initio approximate coupled-cluster singles and doubles $(\mathrm{CC} 2)^{\mathbf{9 6}}$ method red-shifts the vertical excitation energy of $(P, P)$ cis-2 relative to $(P, P)$-trans-1, and whereby it is shown that the $\omega$ B97X-D results are not changed much by the use of a larger basis set than SVP.

Turning to the structural changes during the FC relaxation and considering first the $\omega$ B97X-D data in Table 2, a pronounced lengthening of the central $\mathrm{C} 4-\mathrm{C} 4$ ' bond is observed, that ranges from $0.07-0.08 \AA$ for $(P, P)$-cis-2 to 0.11$0.12 \AA$ for $(P, P)$-trans -1 and shows no particular sensitivity to the presence of a solvent environment. Such bond stretching facilitates photoisomerization and is for both isomers accompanied by substantial torsional motion along the $\alpha$ photoisomerization coordinate. Indeed, during the FC relaxation of $(P, P)$-trans-1, the upper motor part is rotated around the $\mathrm{C} 4-\mathrm{C} 4{ }^{\prime}$ bond by more than $90^{\circ}$, which suggests that much of the photochemical motion of this isomer proceeds without an energy barrier to be overcome. In this connection, fluorescence up-conversion measurements predict that the photochemical processes of this type of molecular motors occur within hundreds of fs, i.e., essentially in a barrierless fashion. ${ }^{97}$ For $(P, P)$-cis-2, in turn, the upper motor part is rotated by $17-22^{\circ}$. Notably, from the associated changes in the $\alpha$ dihedral angles, it can be deduced that the direction of photoinduced torsional motion is the same - counterclockwise - for both isomers, which means that the two photoisomerizations occur in a unidirectional fashion and produce rotary motion during the reaction cycle of 1.
From Table 3 and the calculations with other density functionals than $\omega$ B97X-D, it is found that these support exactly the same conclusions on the FC relaxation as $\omega$ B97X-D, albeit with some quantitative differences between them as to the extent of the photoinduced rotation around the $\mathrm{C} 4-\mathrm{C} 4{ }^{\prime}$ bond. This sensitivity to the choice of method is likely to be a consequence of the flatness of the $S_{1}$ PES along the $\alpha$ coordinate.

In Fig. 2 , all $\omega$ B97X-D $S_{1}$ data points calculated along the photoisomerization coordinate are shown. Based on the foregoing analysis, these calculations were performed in the gas phase. While the full range of possible $\alpha$ dihedral angles are considered $\left[-180^{\circ}\right.$ to $0^{\circ}$ for $(P, P)$-trans $-1 ; 0^{\circ}$ to $180^{\circ}$ for $(P, P)$-cis-2], it should be pointed out that not all of them are photochemically relevant and that, as discussed in Section 2, the photoisomerizations are likely to involve conical intersections at highly twisted geometries where decay to the ground state takes place. Furthermore, although $\omega$ B97X-D has been found to perform well for photoisomerizations around carbon-carbon
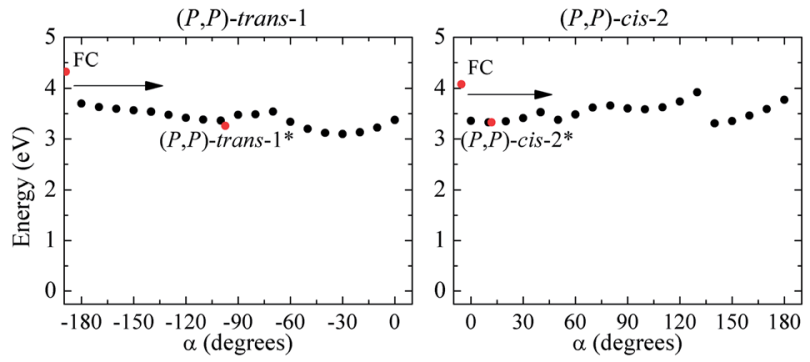

Fig. $2 \omega \mathrm{B} 97 \mathrm{X}-\mathrm{D}$ gas-phase photoisomerization paths for $(P, P)$-trans-1 and $(P, P)$-cis-2 (the direction of photoisomerization is indicated by arrows).

Table 3 Vertical (VEE) and adiabatic (AEE) gas-phase $S_{0} \rightarrow S_{1}$ excitation energies of the $(P, P)$-trans-1 and $(P, P)$-cis-2 isomers of motor 1 and associated changes in geometric parameters during the FC relaxation as obtained with different methods ${ }^{a}$

\begin{tabular}{|c|c|c|c|c|c|c|c|c|c|}
\hline Isomer & Method & \multicolumn{2}{|c|}{ Energies } & \multicolumn{6}{|c|}{ Geometric parameters $\left(S_{0} \rightarrow S_{1}\right)$} \\
\hline & BLYP & 3.02 & 2.84 & 1.374 & 1.404 & 0.030 & 171.4 & 176.7 & 5.3 \\
\hline & B3LYP & 3.70 & 3.11 & 1.360 & 1.433 & 0.073 & 171.1 & -162.5 & 26.4 \\
\hline & PBE0 & 3.84 & 3.53 & 1.356 & 1.409 & 0.053 & 170.9 & 179.7 & 8.8 \\
\hline & $\omega \mathrm{B} 97 \mathrm{X}-\mathrm{D}$ & 4.33 & 3.26 & 1.349 & 1.456 & 0.107 & 171.0 & -97.3 & 91.7 \\
\hline & CIS & 5.06 & 4.36 & 1.339 & 1.446 & 0.107 & 170.6 & -139.0 & 50.4 \\
\hline & Exp. $\lambda_{\max }{ }^{b}$ & 3.80 & - & - & - & - & - & - & \\
\hline \multirow{5}{*}{$(P, P)-c i s-2$} & BP86 & 2.98 & 2.73 & 1.377 & 1.428 & 0.051 & 0.7 & 2.6 & 1.9 \\
\hline & BLYP & 2.97 & 2.79 & 1.378 & 1.418 & 0.040 & 0.6 & 8.2 & 7.6 \\
\hline & B3LYP & 3.60 & 3.13 & 1.364 & 1.430 & 0.066 & -0.1 & 11.1 & 11.2 \\
\hline & CIS & 4.97 & 4.49 & 1.344 & 1.419 & 0.075 & -3.1 & 6.5 & 9.6 \\
\hline & Exp. $\lambda_{\max }{ }^{b}$ & 4.11 & - & - & - & - & - & - & \\
\hline
\end{tabular}

${ }^{a}$ Excitation energies in eV, bond lengths in $\AA$, and dihedral angles in degrees. ${ }^{b}$ Experimental absorption maximum (in eV) from ref. 14. 
double bonds in conjugated systems, ${ }^{\mathbf{8 2 , 8 3}}$ it is a single-reference method and as such is less well suited for explicit location of conical intersections than multi-reference methods like CASSCF. Instead, as outlined in Section 2, the (M,M)-cis-2 and $(M, M)$-trans-1 species whose formation is mediated by the presumed conical intersections were located by starting groundstate geometry optimizations at highly twisted excited-state structures along the photoisomerization paths.

The key feature of the calculated paths in Fig. 2 is their flatness, which is indicative of the extraordinarily fast excitedstate dynamics that these systems exhibit. ${ }^{97}$ Furthermore, following population of the vertically excited FC point, there is a considerable driving force to reach the respective excited-state minimum: $103.2 \mathrm{~kJ} \mathrm{~mol}^{-1}$ for $(P, P)$-trans-1* and $72.4 \mathrm{~kJ} \mathrm{~mol}^{-1}$ for $(P, P)$-cis-2*. Loosely, the somewhat more favorable - both in terms of driving force and kinetics - energetics for the $(P, P)$ trans-1 reaction is consistent with the experimentally observed photoequilibrium "product-over-reactant" ratios for $(M, M)$-cis-2 to $(P, P)$-trans-1 being higher $(95: 5)$ than that for $(M, M)$-trans-1 to $(P, P)$-cis-2 $(90: 10) .{ }^{\mathbf{1 4 , 1 5}}$

\subsection{Thermal helix inversion steps}

In the $(M, M)$-cis-2 and $(M, M)$-trans-1 isomers formed by the photoisomerizations, the $\mathrm{C} 3$ and $\mathrm{C}^{\prime}$ methyl substituents are forced to adopt a strained equatorial orientation. As a result, the subsequent thermal helix inversions that regain the preferred axial orientation for the methyl groups and produce the parent $(P, P)$-cis-2 and $(P, P)$-trans-1 isomers, will occur spontaneously. ${ }^{22}$ One can envision two different reaction mechanisms for these processes - stepwise or concerted. In a stepwise mechanism, which is shown in Fig. 3, the helicities of the two halves of the molecule change one at a time, whereby also the C3 and C3' methyl substituents change from equatorial to axial orientation one at a time. This means that the helix inversion proceeds via an $(M, P)$-cis-2 intermediate in the first half of the rotary cycle and an $(M, P)$-trans-1 intermediate in the second, and that the overall rotary cycle involves six distinguishable steps. In a concerted mechanism, on the other hand, the helicities of the two molecular moieties change simultaneously and no such intermediates come into play. Analyzing ${ }^{1} \mathrm{H}-\mathrm{NMR}$ spectra and $\mathrm{X}$-ray diffraction data for a modified version of Feringa's firstgeneration motor 1 with $i$-propyl rather than methyl groups at C3 and C3', ter Wiel et al. were first to report evidence in favor of one mechanism (stepwise) over the other (concerted). ${ }^{\mathbf{2 0}}$

Some mechanistic aspects of the thermal helix inversions have been explored in previous computational studies. For example, in a gas-phase study focusing primarily on modeling the photochemical steps of $\mathbf{1}$ by means of Car-Parrinello molecular dynamics simulations but investigating also the thermal reactions using static quantum chemical calculations (the thermal reactions are much too slow to be modeled by Carr-Parinello simulations), Grimm et al. considered a stepwise mechanism and explored the relevant parts of the $S_{0}$ PES at the semiempirical AM1 level of theory. ${ }^{39}$ While these researchers did not explicitly locate transition structures for the thermal steps, as we have done in the present work, they performed a

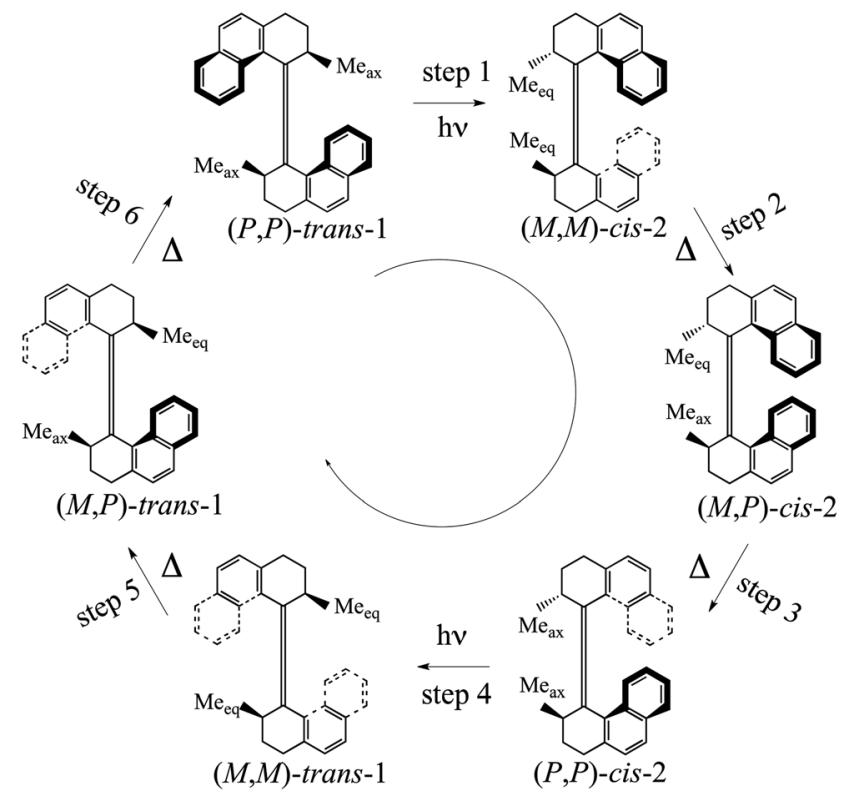

Fig. 3 Tentative mechanism for the rotary cycle of motor 1 with the thermal helix inversions proceeding in a stepwise fashion.

series of constrained geometry optimizations to obtain a twodimensional PES with respect to torsional motion along the $\beta$ and $\beta^{\prime}$ coordinates defined in Table 1 . Thereby, they estimated that the potential energy (thus neglecting zero-point vibrational and thermal corrections to the potential energy) barriers for steps 2 and 3 in Fig. 3 amount to 69-88 and 50-59 kJ mol${ }^{-1}$, respectively. ${ }^{39}$ As a comparison, the experimental study by ter Wiel et al. found that the $(M, M)$-cis-2 $\rightarrow(P, P)$-cis-2 conversion (i.e., steps $2+3$ ) of 1 in hexane has an overall free-energy barrier of $91 \mathrm{~kJ} \mathrm{~mol}^{-1} \cdot{ }^{20}$ For the $(M, M)$-trans-1 $\rightarrow(P, P)$-trans-1 reaction, in turn, they reported an overall barrier of $107 \mathrm{~kJ} \mathrm{~mol}^{-1} .^{20} \mathrm{In}$ another computational study, Pérez-Hernández and González carried out an exhaustive Monte Carlo-like conformational search for a second-generation motor and a redesigned version thereof. ${ }^{43}$

In this work, we first embarked on locating all of the $\mathrm{S}_{0}$ stationary points of the stepwise reaction in Fig. 3 by performing all of the requisite calculations (geometry optimizations and frequency and IRC calculations) using both $\omega$ B97X-D and B3LYP, and considering both gas phase and solution environments. Besides the parent $(P, P)$-trans-1 and $(P, P)$-cis-2 isomers, the photoisomerized $(M, M)$-cis-2 and $(M, M)$-trans- 1 isomers, and the $(M, P)$-cis-2 and $(M, P)$-trans-1 intermediates, these stationary points also include the relevant transition structures, which are denoted $\mathrm{TS}_{2}$ (step 2), $\mathrm{TS}_{3}$ (step 3), $\mathrm{TS}_{5}$ (step 5) and $\mathrm{TS}_{6}$ (step 6). The results of these calculations are presented in Fig. 4. Since $\omega$ B97X-D and B3LYP again were found to produce similar energetics and solvent effects again were found to be small, Fig. 4 shows only the $\omega$ B97X-D gas-phase results, together with the corresponding results for the photochemical steps. The results obtained at the other levels of theory are included in Table S4 of the ESI. $\dagger$

Starting from the photoisomerized $(M, M)$-cis-2 isomer in the first half of the rotary cycle, the first helix inversion to form the 
$(M, P)$-cis-2 intermediate via $\mathrm{TS}_{2}$ is estimated to have a freeenergy barrier of $\sim 101 \mathrm{~kJ} \mathrm{~mol}^{-1}$, which is higher than the $\sim 83 \mathrm{~kJ}$ $\mathrm{mol}^{-1}$ barrier for the subsequent helix inversion that, via $\mathrm{TS}_{3}$, brings the motor to the $(P, P)$-cis-2 station and completes the first half of the rotary cycle. Thus, for the $(M, M)$-cis-2 $\rightarrow(M, P)$-cis-2 $\rightarrow(P, P)$-cis-2 process, the calculations predict that the first step is the rate-determining one, and ascribe to this step a freeenergy barrier $\left(\sim 101 \mathrm{~kJ} \mathrm{~mol}^{-1}\right)$ that agrees well with the aforementioned experimental barrier of $91 \mathrm{~kJ} \mathrm{~mol}^{-1}$ between $(M, M)$-cis-2 and $(P, P)$-cis-2. ${ }^{\mathbf{2 0}}$

As for the calculated free-energy lowering upon the change in orientation of the $\mathrm{C} 3$ and $\mathrm{C} 3{ }^{\prime}$ methyl groups from strained equatorial in $(M, M)$-cis-2 to favorable axial in $(P, P)$-cis-2, this amounts to $\sim 55 \mathrm{~kJ} \mathrm{~mol}^{-1}$. Such a sizable driving force guarantees that this reaction occurs spontaneously, and plays a key role for the unidirectional motion of the motor by rendering the $(P, P)$-cis-2 $\rightarrow(M, M)$-cis-2 back reaction thermodynamically unviable. ${ }^{22}$ Thereby, the rotary cycle becomes irreversible.

(a)

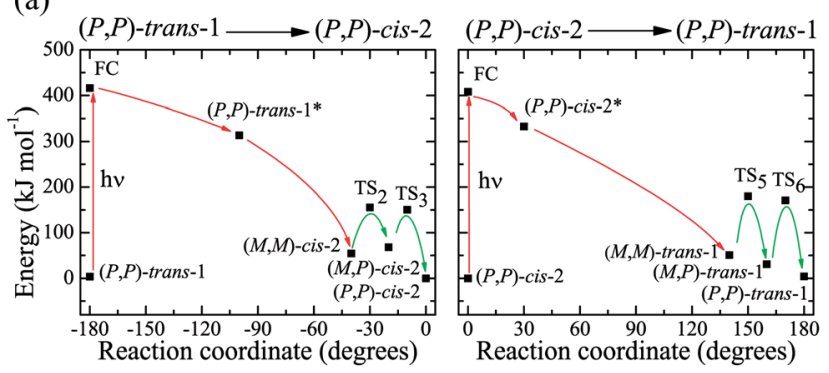

(b)

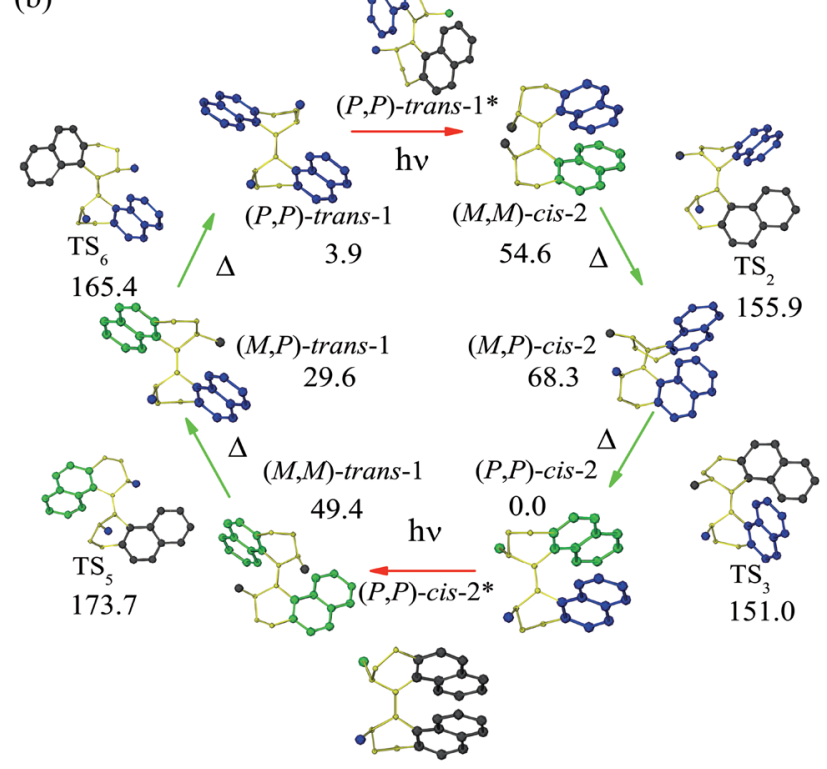

Fig. 4 (a) $\omega$ B97X-D gas-phase energy profile for the rotary cycle of motor 1 with photochemical (electronic energies) and thermal (free energies) steps indicated by red and green arrows, respectively (b) $\omega \mathrm{B} 97 \mathrm{X}-\mathrm{D}$ gas-phase stationary points and their relative free energies (in $\mathrm{kJ} \mathrm{mol}^{-1}$ ) along the rotary cycle of motor 1 with pointing-out, pointing-in, and planar orientations of the naphthyl rings indicated by blue, green, and black colors, respectively.
While, as noted above, experimental data for an $i$-propyl substituted motor has been taken as evidence for a stepwise mechanism for the thermal helix inversions, ${ }^{20}$ there is to the best of our knowledge no experimental data on how much higher in energy the $(M, P)$-cis-2 intermediate lies than the $(P, P)$ cis-2 isomer, that can serve as reference for the calculated value of $\sim 68 \mathrm{~kJ} \mathrm{~mol}^{-1}$. However, this value is in very good accord with a previous DFT-based estimate of $63-65 \mathrm{~kJ} \mathrm{~mol}^{-1} \cdot{ }^{39}$

Turning to the second half of the rotary cycle in Fig. 4 and the thermal transformation of the photoisomerized $(M, M)$-trans-1 isomer into $(P, P)$-trans-1, there are both differences and similarities between this free-energy profile and that of the first half cycle just described. As for differences, the initial helix inversion that forms the $(M, P)$-trans- 1 intermediate via $\mathrm{TS}_{5}$ is estimated to have a lower free-energy barrier $\left(\sim 124 \mathrm{~kJ} \mathrm{~mol}^{-1}\right)$ than the subsequent helix inversion that completes the full rotary cycle via $\mathrm{TS}_{6}\left(\sim 136 \mathrm{~kJ} \mathrm{~mol}^{-1}\right)$. Thus, for this half cycle, the calculations suggest that the second helix inversion is the rate-determining step. The $\sim 136 \mathrm{~kJ} \mathrm{~mol}^{-1}$ free-energy barrier associated with this step is in reasonable agreement with the $\sim 107 \mathrm{~kJ}$ $\mathrm{mol}^{-1}$ barrier predicted by experiments for the overall $(M, M)$ trans-1 $\rightarrow(P, P)$-trans-1 process. $^{20}$

As for similarities between the two half cycles, the calculated $\sim 46 \mathrm{~kJ} \mathrm{~mol}^{-1}$ free-energy lowering from the two thermal steps of the second half cycle compares well with the corresponding value of $\sim 55 \mathrm{~kJ} \mathrm{~mol}^{-1}$ for the two thermal steps of the first half cycle. Furthermore, the calculated $\sim 26 \mathrm{~kJ} \mathrm{~mol}^{-1}$ free-energy difference between the $(M, P)$-trans- 1 intermediate and the $(P, P)$ trans-1 isomer agrees just as well with what was reported in the DFT-based study referred to above (28-31 $\left.\mathrm{kJ} \mathrm{mol}^{-1}\right),{ }^{39}$ as does the calculated free-energy difference between the $(M, P)$-cis-2 intermediate and the $(P, P)$-cis-2 isomer.

Besides yielding rate-determining free-energy barriers of $\sim 101$ and $\sim 136 \mathrm{~kJ} \mathrm{~mol}^{-1}$ for the first and second half cycles that agree well and reasonably, respectively, with the experimental values of $\sim 91$ and $\sim 107 \mathrm{~kJ} \mathrm{~mol}^{-1}$, $^{20}$ it is clear that the $\omega$ B97X-D calculations also reinforce the experimental prediction that the second half cycle is slower than the first. ${ }^{20}$ This conclusion is corroborated by the calculation of all ground-state stationary points of motor 1 using a range of alternative density functionals, as detailed in Table S2 of the ESI. $\dagger$ Indeed, similarly to $\omega \mathrm{B} 97 \mathrm{X}-\mathrm{D}$, all of these methods give higher barriers for the helix inversions of the second half cycle. Moreover, in further agreement with the $\omega$ B97X-D results, they uniformly predict that the first helix inversion is rate-determining in the first half cycle, and that the second helix inversion is rate-determining in the second half cycle.

Interestingly, for the $i$-propyl-substituted motor for which the stepwise mechanism explored by the preceding calculations was originally implicated, ${ }^{\mathbf{2 0}}$ it was possible to obtain experimental estimates of the free-energy barriers for the individual helix inversions of the second half cycle that, in line with our calculated results for motor $\mathbf{1}$, indicate that the second inversion (barrier of $131 \mathrm{~kJ} \mathrm{~mol}^{-1}$ ) is slower than the first (barrier of $\left.124 \mathrm{~kJ} \mathrm{~mol}^{-1}\right) .^{20}$ Hence, it is of interest to test whether our computational approach can reproduce also this finding. Such calculations on the $i$-propyl-substituted motor are summarized 
in Table S5 of the ESI. $\uparrow$ Pleasingly, it is found that this is indeed the case, albeit that the $124 \mathrm{~kJ} \mathrm{~mol}^{-1}$ barrier for the $(M, M)$-trans$1 \rightarrow(M, P)$-trans -1 inversion is underestimated by $16-28 \mathrm{~kJ}$ $\mathrm{mol}^{-1}$ and the $131 \mathrm{~kJ} \mathrm{~mol}^{-1}$ barrier for the $(M, P)$-trans $-1 \rightarrow(P, P)$ trans -1 inversion is overestimated by $13-29 \mathrm{~kJ} \mathrm{~mol}^{-1}$.

Finally, as for the concerted mechanism, our calculations did provide two indications supporting the experimental view that this mechanism is less relevant than the stepwise mechanism, ${ }^{20}$ albeit not in the form of explicitly located concerted transition structures. The first indication comes from the twodimensional $\omega$ B97X-D and B3LYP $S_{0}$ PESs for torsional motion along the $\beta$ and $\beta^{\prime}$ coordinates in Fig. S1 of the ESI, $\dagger$ which clearly suggest that the energy barriers for a concerted process are higher than those for a stepwise process. The second, related, indication is the observation that any attempt to optimize a concerted transition structure starting from a structure "close" to the highest-energy point along a tentative concerted reaction path in Fig. $\mathrm{S} 1, \dagger$ invariably converged to a transition structure along the stepwise reaction path. Thus, this path appears energetically preferable over the concerted ditto.

\subsection{Faster-rotating molecular motors}

One of the key challenges in the development of overcrowded alkene-based rotary molecular motors is to maximize their rate of rotation. ${ }^{22}$ Since the photochemical steps of the rotary cycle proceed extraordinarily fast, ${ }^{97}$ it is clear that it is the thermal helix inversions that limit the overall rate. For example, because of the substantial free-energy barriers of these steps (as shown both experimentally ${ }^{20}$ and, herein, computationally), the halflife of motor 1 exceeds one week at room temperature, which means that heating $\left(>60^{\circ}\right)$ is required to generate continual and repetitive rotary motion around the central carbon-carbon double bond. ${ }^{22}$ Accordingly, one strategy for achieving rate acceleration is to lower the thermal barriers. That such endeavors can be guided by computational studies of the present type is, we believe, demonstrated by the results presented in Section 3.3.

In this section, we will further illustrate this point by reporting calculations on the second-generation overcrowded alkene-based rotary motor 2 shown in Scheme 2, whose thermal barriers are much lower than those of $\mathbf{1}$ and which is able to sustain $\mathrm{MHz}$ rotational frequencies at ambient temperatures. ${ }^{25}$ Moreover, we will also report calculations on our own suggestion 3 for a slightly modified version of motor 2 that, we reasoned, should exhibit even lower thermal barriers. Interestingly, it will be inferred from these calculations that this prediction appears to be correct. As can be seen in Scheme 2, the only difference between motors 2 and 3 is that the C5 methyl group of 2 is replaced by a methoxy group in 3 . Although introducing a group of similar size, the idea was that such a substitution should nonetheless reduce the steric hindrance to be overcome during the thermal steps, by virtue of the methoxy group being positioned further away from the stator than the methyl group.

In second-generation rotary motors, a number of different approaches are utilized to improve the kinetics of the thermal helix inversion steps, ${ }^{\mathbf{6}, 16-27}$ including some of which are implemented in motor 2. For example, by contracting the sixmembered rings fused to the rotation axis into five-membered rings, or by replacing the naphthalene moieties with phenyl groups, the steric demands on the helix inversions can be mitigated. An analogous effect can be achieved by variation of the stereogenic substituents, which may also alter the thermal barriers by stabilizing or destabilizing some isomers of the rotary cycle more than others. It is also possible to influence the thermal barriers through the introduction of different bridging rotator and/or stator atoms (e.g., the sulfur atom in 2) with varying electron-donating/withdrawing capabilities.

The key results from the calculations on motors $\mathbf{2}$ and $\mathbf{3}$ are summarized in Table 4. In the interest of brevity, this summary focuses exclusively on the rate-determining thermal barriers in the rotary half cycles, where trans $\rightarrow$ cis denotes the half cycle initiated by light absorption of the parent trans isomer, and cis $\rightarrow$ trans denotes the half cycle initiated by light absorption of the parent cis isomer. Results from excited-state calculations indicating that the photoisomerizations of the two parent isomers occur in a unidirectional fashion, and thus produce rotary motion, are included in Fig. S2 of the ESI. $\dagger$

From Table 4, one first notes that the calculations reproduce the experimental observation ${ }^{25}$ that motor 2 is able to reach much higher rotational frequencies than the original motor $\mathbf{1}$. Specifically, for both half cycles, all calculated estimates are within $\sim 5 \mathrm{~kJ} \mathrm{~mol}^{-1}$ agreement with the observed rate-determining free-energy barrier, which for both half cycles is appreciably lower $\left(\sim 35 \mathrm{~kJ} \mathrm{~mol}^{-1}\right)$ than what experiments ${ }^{20}$ and our foregoing calculations assigned to 1 . The fact that the barriers are virtually identical in the two half cycles, whereas for 1 they were quite different, is easily understood through inspection of the optimized reactant and transition structures of motor 2 in Fig. 5. Indeed, from these it is clear that the stator methoxy group is sterically inactive not only in the reactants that precede the thermal helix inversions (shown in red color), but also in the rate-determining transition structures (shown in green color). Hence, while this methoxy group makes the stator asymmetric, the stator is anyhow "symmetric" in terms of how its terminal phenyl moieties interact sterically. As a consequence, the thermal barriers in one of the half cycles are very similar to those in the other. For motor 1, on the other hand, the

Table 4 Rate-determining $\omega$ B97X-D and B3LYP free-energy barriers (in $\mathrm{kJ} \mathrm{mol}^{-1}$ ) for the thermal helix inversion steps of motors 2 and $3^{a}$

\begin{tabular}{|c|c|c|c|c|c|c|}
\hline \multirow[b]{2}{*}{ Motor } & \multirow[b]{2}{*}{ Half cycle } & \multicolumn{2}{|c|}{$\omega \mathrm{B} 97 \mathrm{X}-\mathrm{D}$} & \multicolumn{2}{|c|}{ B3LYP } & \multirow{2}{*}{$\frac{\text { Exp. }^{b}}{\text { Sol. }^{d}}$} \\
\hline & & $\operatorname{Gas}^{c}$ & Sol. ${ }^{d}$ & $\operatorname{Gas}^{c}$ & Sol. ${ }^{d}$ & \\
\hline \multirow[t]{2}{*}{2} & trans $\rightarrow$ cis & 41.4 & 37.1 & 34.8 & 30.8 & 35.0 \\
\hline & cis $\rightarrow$ trans & 40.0 & 37.1 & 35.2 & 30.0 & 34.2 \\
\hline \multirow[t]{2}{*}{3} & trans $\rightarrow$ cis & 23.9 & 17.1 & 19.7 & 12.6 & $-^{e}$ \\
\hline & cis $\rightarrow$ trans & 22.9 & 15.2 & 17.4 & 10.4 & $-^{e}$ \\
\hline
\end{tabular}

${ }^{a}$ Similar results obtained with larger basis sets than SVP are presented in Table S6 of the ESI. ${ }^{b}$ Experimental data from ref. $25 .{ }^{c}$ Gas-phase environment. ${ }^{d}$ Dichloromethane solvent environment. ${ }^{e}$ Experimental data not available. 
steric interactions are different in the two half cycles, whereby the barriers are different too.

Finally, as for the calculations on motor 3, the results in Table 4 do predict, as discussed above, a lowering of the ratedetermining free-energy barriers upon replacement of the C5 methyl group (in 2) with a methoxy group (in 3). In fact, all levels of theory estimate that the barriers for 3 are $15-20 \mathrm{~kJ} \mathrm{~mol}^{-1}$ lower. Given the small errors with which the calculations on 2 reproduce the corresponding experimental barriers, we believe it is well-founded to conclude that $\mathbf{3}$ is a promising candidate for an overcrowded alkene-based rotary molecular motor capable of surpassing 2 in rotational frequency.

\section{Conclusions}

In summary, we have reported a computational study illustrating the potential of DFT methods to contribute to the ongoing development of synthetic overcrowded alkene-based light-driven rotary molecular motors operating in the $\mathrm{MHz}$ regime and beyond. To date, this development has produced a series of motors ${ }^{6,16-27}$ that achieve much higher rotational frequencies than the original motor (motor 1$)^{14,15}$ of this type, with the current record $(>12 \mathrm{MHz}$ under optimal conditions in solution) held by a system featuring a five-membered ring upper-half and a six-membered ring lower-half. ${ }^{27}$

Exploring the rotary cycle of $\mathbf{1}$ for benchmark purposes and employing $\omega$ B97X-D and B3LYP as "workhorse" methods (but using also a number of alternative density functionals for some of the calculations), it is first found that these methods are able to reproduce crystallographic ${ }^{14}$ and $\mathrm{UV}$-vis absorption data ${ }^{14}$ for

\section{Motor 2}

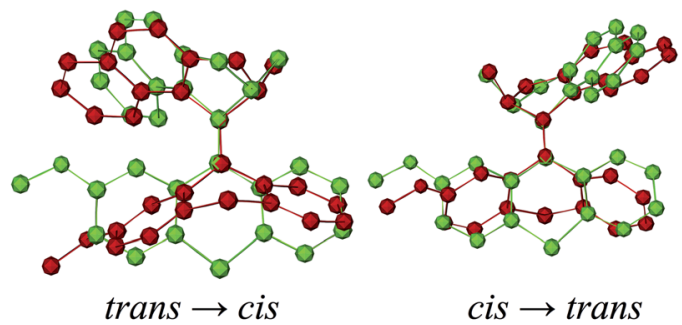

Motor 3

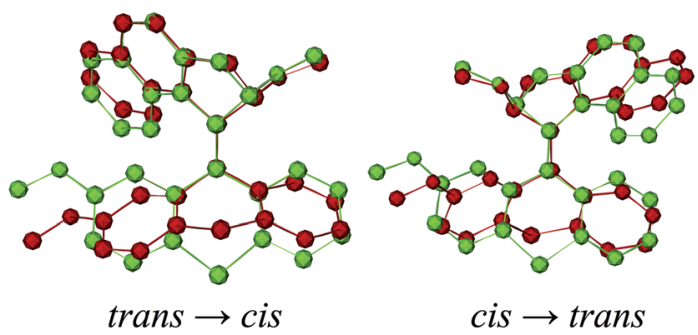

Fig. 5 Optimized $\omega$ B97X-D gas-phase reactant (in red color) and transition (in green color) structures for the rate-determining thermal helix inversion steps of motors 2 and 3 . the parent $(P, P)$-trans-1 and $(P, P)$-cis-2 isomers with reasonable accuracy. Furthermore, the distinctly directional light-induced torsional motion of $(P, P)$-trans-1 and $(P, P)$-cis-2 with respect to the central $\mathrm{C} 4-\mathrm{C} 4^{\prime}$ double bond shown by the calculations is consistent with the fact that the photoisomerizations of these isomers afford a full $360^{\circ}$ unidirectional rotation.

As for the thermal helix inversion steps, which are clearly what limit the overall rotation rates attainable by overcrowded alkene-based motors ${ }^{97}$ and hold key to their rate acceleration, the calculations on motor 1 support and complement available experimental data ${ }^{20}$ on the preference of a stepwise mechanism over a concerted ditto. Moreover, the calculations predict that the first helix inversion is rate-determining in the $(P, P)$-trans-1 $\rightarrow(P, P)$-cis-2 rotary half cycle and the second helix inversion in the $(P, P)$-cis-2 $\rightarrow(P, P)$-trans-1 half cycle, and provide free-energy barriers that are in qualitative accordance with the corresponding experimental estimates. ${ }^{20}$

Second, investigating the $\mathrm{MHz}-\mathrm{capabl}^{25}$ second-generation motor 2 to further assess the merits of the computational methodology, it is found that both $\omega$ B97X-D and B3LYP can accurately reproduce the much lower rate-determining thermal barriers of around $\sim 35 \mathrm{~kJ} \mathrm{~mol}^{-1}$ ascribed to this rotary cycle. Indeed, the calculated barriers agree to within $\sim 5 \mathrm{~kJ} \mathrm{~mol}^{-1}$ with the experimental values ${ }^{25}$ although partly because of a fortuitous cancellation of errors.

Finally, applying the computational methodology to our own suggestion for a new second-generation motor (motor 3) hypothesized to exhibit even lower thermal barriers than 2 because of the substitution of the rotator methyl group with a methoxy group, this hypothesis does indeed seem correct. Specifically, it is predicted that such a substitution would lower the rate-determining barriers by a further $15-20 \mathrm{~kJ} \mathrm{~mol}^{-1}$. Hence, if readily synthesizable, 3 appears to be a potent candidate for a fast-rotating molecular motor.

\section{Acknowledgements}

We gratefully acknowledge financial support from Linköping University, the Swedish Research Council, the Olle Engkvist Foundation and the Wenner-Gren Foundations; grants of computing time at the National Supercomputer Centre (NSC) in Linköping; and valuable discussions with Olle Falklöf.

\section{Notes and references}

1 W. R. Browne and B. L. Feringa, Nat. Nanotechnol., 2006, 1, 25-35.

2 E. R. Kay, D. A. Leigh and F. Zerbetto, Angew. Chem., Int. Ed., 2007, 46, 72-191.

3 V. Balzani, A. Credi and M. Venturi, Chem. Soc. Rev., 2009, 38, 1542-1550.

4 D. A. Leigh, J. K. Y. Wong, F. Dehez and F. Zerbetto, Nature, 2003, 424, 174-179.

5 G. S. Kottas, L. I. Clarke, D. Horinek and J. Michl, Chem. Rev., 2005, 105, 1281-1376.

6 B. L. Feringa, J. Org. Chem., 2007, 72, 6635-6652.

7 J. Michl and E. C. H. Sykes, ACS Nano, 2009, 3, 1042-1048. 
8 M. R. Panman, P. Bodis, D. J. Shaw, B. H. Bakker, A. C. Newton, E. R. Kay, A. M. Brouwer, W. Jan Buma, D. A. Leigh and S. Woutersen, Science, 2010, 328, 1255-1258.

9 T. Kudernac, N. Ruangsupapichat, M. Parschau, B. Maciá, N. Katsonis, S. R. Harutyunyan, K.-H. Ernst and B. L. Feringa, Nature, 2011, 479, 208-211.

10 E. C. H. Sykes, Angew. Chem., Int. Ed., 2012, 51, 4277-4278. 11 K. Kinbara and T. Aida, Chem. Rev., 2005, 105, 1377-1400.

12 D. Stock, A. G. W. Leslie and J. E. Walker, Science, 1999, 286, 1700-1705.

13 T. R. Kelly, H. De Silva and R. A. Silva, Nature, 1999, 401, 150152.

14 N. Harada, N. Koumura and B. L. Feringa, J. Am. Chem. Soc., 1997, 119, 7256-7264.

15 N. Koumura, R. W. J. Zijlstra, R. A. van Delden, N. Harada and B. Feringa, Nature, 1999, 401, 152-155.

16 B. L. Feringa, N. Koumura, R. A. van Delden and M. K. J. ter Wiel, Appl. Phys. A: Mater. Sci. Process., 2002, 75, 301-308.

17 N. Koumura, E. M. Geertsema, M. B. van Gelder, A. Meetsma and B. L. Feringa, J. Am. Chem. Soc., 2002, 124, 5037-5051.

18 R. A. van Delden, N. Koumura, A. Schoevaars, A. Meetsma and B. L. Feringa, Org. Biomol. Chem., 2003, 1, 33-35.

19 M. K. J. ter Wiel, R. A. van Delden, A. Meetsma and B. L. Feringa, J. Am. Chem. Soc., 2003, 125, 15076-15086.

20 M. K. J. ter Wiel, R. A. van Delden, A. Meetsma and B. L. Feringa, J. Am. Chem. Soc., 2005, 127, 14208-14222.

21 D. Pijper, R. A. van Delden, A. Meetsma and B. L. Feringa, J. Am. Chem. Soc., 2005, 127, 17612-17613.

22 M. M. Pollard, M. Klok, D. Pijper and B. L. Feringa, Adv. Funct. Mater., 2007, 17, 718-729.

23 M. Klok, M. Walko, E. M. Geertsema, N. Ruangsupapichat, J. C. M. Kistemaker, A. Meetsma and B. L. Feringa, Chem. Eur. J., 2008, 14, 11183-11193.

24 M. M. Pollard, A. Meetsma and B. L. Feringa, Org. Biomol. Chem., 2008, 6, 507-512.

25 M. Klok, N. Boyle, M. T. Pryce, A. Meetsma, W. R. Browne and B. L. Feringa, J. Am. Chem. Soc., 2008, 130, 10484-10485.

26 A. A. Kulago, E. M. Mes, M. Klok, A. Meetsma, A. M. Brouwer and B. L. Feringa, J. Org. Chem., 2010, 75, 666-679.

27 J. Vachon, G. T. Carroll, M. M. Pollard, E. M. Mes, A. M. Brouwer and B. L. Feringa, Photochem. Photobiol. Sci., 2014, 13, 241-246.

28 R. A. van Delden, M. K. J. ter Wiel, M. M. Pollard, J. Vicario, N. Koumura and B. L. Feringa, Nature, 2005, 437, 1337-1340.

29 N. Katsonis, M. Lubomska, M. M. Pollard, B. L. Feringa and P. Rudolf, Prog. Surf. Sci., 2007, 82, 407-434.

30 J. Vacek and J. Michl, Adv. Funct. Mater., 2007, 17, 730-739.

31 G. London, G. T. Carroll and B. L. Feringa, Org. Biomol. Chem., 2013, 42, 3477-3483.

32 A. Strambi, B. Durbeej, N. Ferré and M. Olivucci, Proc. Natl. Acad. Sci. U. S. A., 2010, 107, 21322-21326.

33 R. Eelkema, M. M. Pollard, J. Vicario, N. Katsonis, B. S. Ramon, C. W. M. Bastiaansen, D. J. Broer and B. L. Feringa, Nature, 2006, 440, 163.

34 P.-T. Chiang, J. Mielke, J. Godoy, J. M. Guerrero, L. B. Alemany, C. J. Villagómez, A. Saywell, L. Grill and J. M. Tour, ACS Nano, 2012, 6, 592-597.
35 M. Klok, W. R. Browne and B. L. Feringa, Phys. Chem. Chem. Phys., 2009, 11, 9124-9131.

36 Y. Amatatsu, J. Phys. Chem. A, 2011, 115, 13611-13618.

37 Y. Amatatsu, J. Phys. Chem. A, 2012, 116, 10182-10193.

38 C. García-Iriepa, M. Marazzi, F. Zapata, A. Valentini, D. Sampedro and L. M. Frutos, J. Phys. Chem. Lett., 2013, 4, 1389-1396.

39 S. Grimm, C. Bräuchle and I. Frank, ChemPhysChem, 2005, 6, 1943-1947.

40 A. Kazaryan and M. Filatov, J. Phys. Chem. A, 2009, 113, 11630-11634.

41 A. Kazaryan, Z. Lan, L. V. Schäfer, W. Thiel and M. Filatov, J. Chem. Theory Comput., 2011, 7, 2189-2199.

42 F. Liu and K. Morokuma, J. Am. Chem. Soc., 2012, 134, 48644876.

43 G. Pérez-Hernández and L. González, Phys. Chem. Chem. Phys., 2010, 12, 12279-12289.

44 E. Runge and E. K. U. Gross, Phys. Rev. Lett., 1984, 52, 9971000.

45 R. Bauernschmitt and R. Ahlrichs, Chem. Phys. Lett., 1996, 256, 454-464.

46 M. E. Casida, C. Jamorski, K. C. Casida and D. R. Salahub, J. Chem. Phys., 1998, 108, 4439-4449.

47 R. E. Stratmann, G. E. Scuseria and M. J. Frisch, J. Chem. Phys., 1998, 109, 8218-8224.

48 M. A. L. Marques and E. K. U. Gross, Annu. Rev. Phys. Chem., 2004, 55, 427-455.

49 A. Dreuw and M. Head-Gordon, Chem. Rev., 2005, 105, 40094037.

50 M. E. Casida, J. Mol. Struct.: THEOCHEM, 2009, 914, 3-18.

51 C. T. Lee, W. T. Yang and R. G. Parr, Phys. Rev. B: Condens. Matter Mater. Phys., 1988, 37, 785-789.

52 A. D. Becke, J. Chem. Phys., 1993, 98, 5648-5652.

53 P. J. Stephens, F. J. Devlin, C. F. Chabalowski and M. J. Frisch, J. Phys. Chem., 1994, 98, 11623-11627.

54 J. D. Chai and M. Head-Gordon, Phys. Chem. Chem. Phys., 2008, 10, 6615-6620.

55 A. Schäfer, H. Horn and R. Ahlrichs, J. Chem. Phys., 1992, 97, 2571-2577.

56 E. Cancès, B. Mennucci and J. Tomasi, J. Chem. Phys., 1997, 107, 3032-3041.

57 J. Tomasi, B. Mennucci and R. Cammi, Chem. Rev., 2005, 105, 2999-3094.

58 C. van Caillie and R. D. Amos, Chem. Phys. Lett., 1999, 308, 249-255.

59 F. Furche and R. Ahlrichs, J. Chem. Phys., 2002, 117, 74337447.

60 G. Scalmani, M. J. Frisch, B. Mennucci, J. Tomasi, R. Cammi and V. Barone, J. Chem. Phys., 2006, 124, 094107.

61 M. Chiba, T. Tsuneda and K. Hirao, J. Chem. Phys., 2006, 124, 144106.

62 A. Cembran, F. Bernardi, M. Garavelli, L. Gagliardi and G. Orlandi, J. Am. Chem. Soc., 2004, 126, 3234-3243.

63 B. Durbeej, O. A. Borg and L. A. Eriksson, Phys. Chem. Chem. Phys., 2004, 6, 5066-5073.

$64 \mathrm{M}$. Olivucci and A. Sinicropi, in Theoretical and Computational Chemistry: Computational Photochemistry, ed. 
M. Olivucci, Elsevier, Amsterdam, 2005, vol. 16, ch. 1, pp. 133.

65 B. G. Levine and T. J. Martínez, Annu. Rev. Phys. Chem., 2007, 58, 613-634.

66 L. M. Frutos, T. Andruniów, F. Santoro, N. Ferré and M. Olivucci, Proc. Natl. Acad. Sci. U. S. A., 2007, 104, 7764-7769.

67 M. A. Robb, in Advanced Series in Physical Chemistry: Conical Intersections - Theory, Computation and Experiment, ed. W. Domcke, D. R. Yarkony and H. Köppel, World Scientific Publishing Co., Singapore, 2011, vol. 17, ch. 1, pp. 3-50.

68 B. G. Levine, C. Ko, J. Quenneville and T. J. Martínez, Mol. Phys., 2006, 104, 1039-1051.

69 B. Kaduk and T. van Voorhis, J. Chem. Phys., 2010, 133, 061102.

70 N. Minezawa and M. S. Gordon, J. Chem. Phys., 2012, 137, 034116.

71 R. Kobayashi and R. D. Amos, Mol. Phys., 2013, 111, 15741579.

72 Y. Harabuchi, S. Maeda, T. Taketsugu, N. Minezawa and K. Morokuma, J. Chem. Theory Comput., 2013, 9, 4116-4123. 73 B. O. Roos and P. R. Taylor, Chem. Phys., 1980, 48, 157-173. 74 F. Bernardi, M. Olivucci and M. A. Robb, Chem. Soc. Rev., 1996, 25, 321-328.

75 H. C. Cheol, K. Miklos and K. Alfred, Chem. Phys. Lett., 1997, 276, 266-268.

76 D. J. Tozer, R. D. Amos, N. C. Handy, B. O. Roos and L. Serrano-Andrés, Mol. Phys., 1999, 97, 859-868.

77 H. Iikura, T. Tsuneda, T. Yanai and K. Hirao, J. Chem. Phys., 2001, 115, 3540-3544.

78 Y. Tawada, T. Tsuneda, S. Yanagisawa, T. Yanai and K. Hirao, J. Chem. Phys., 2004, 120, 8425-8433.

79 T. Yanai, D. P. Tew and N. C. Handy, Chem. Phys. Lett., 2004, 393, 51-57.

80 O. A. Vydrov and G. E. Scuseria, J. Chem. Phys., 2006, 125, 234109.

81 J. D. Chai and M. Head-Gordon, J. Chem. Phys., 2008, 128, 084106.

82 I. V. Rostov, R. D. Amos, R. Kobayashi, G. Scalmani and M. J. Frisch, J. Phys. Chem. B, 2010, 114, 5547-5555.

83 I. V. Rostov, R. Kobayashi and R. D. Amos, Mol. Phys., 2012, 110, 2329-2336.

84 S. Grimme, J. Comput. Chem., 2004, 25, 1463-1473.
85 J. Antony and S. Grimme, Phys. Chem. Chem. Phys., 2006, 8, 5287-5293.

86 J. P. Perdew, Phys. Rev. B: Condens. Matter Mater. Phys., 1986, 33, 8822-8824.

87 A. D. Becke, Phys. Rev. A, 1988, 38, 3098-3100.

88 C. Adamo and V. Barone, J. Chem. Phys., 1999, 110, 61586170.

89 Y. Zhao and D. G. Truhlar, Theor. Chem. Acc., 2008, 120, 215241.

90 J. B. Foresman, M. Head-Gordon, J. A. Pople and M. J. Frisch, J. Phys. Chem., 1992, 96, 135-149.

91 H. P. Hratchian and H. B. Schlegel, J. Chem. Phys., 2004, 120, 9918-9924.

92 M. J. Frisch, G. W. Trucks, H. B. Schlegel, G. E. Scuseria, M. A. Robb, J. R. Cheeseman, G. Scalmani, V. Barone, B. Mennucci, G. A. Petersson, H. Nakatsuji, M. Caricato, X. Li, H. P. Hratchian, A. F. Izmaylov, J. Bloino, G. Zheng, J. L. Sonnenberg, M. Hada, M. Ehara, K. Toyota, R. Fukuda, J. Hasegawa, M. Ishida, T. Nakajima, Y. Honda, O. Kitao, H. Nakai, T. Vreven, J. A. Montgomery, J. E. Peralta, F. Ogliaro, M. Bearpark, J. J. Heyd, E. Brothers, K. N. Kudin, V. N. Staroverov, R. Kobayashi, J. Normand, K. Raghavachari, A. Rendell, J. C. Burant, S. S. Iyengar, J. Tomasi, M. Cossi, N. Rega, J. M. Millam, M. Klene, J. E. Knox, J. B. Cross, V. Bakken, C. Adamo, J. Jaramillo, R. Gomperts, R. E. Stratmann, O. Yazyev, A. J. Austin, R. Cammi, C. Pomelli, J. W. Ochterski, R. L. Martin, K. Morokuma, V. G. Zakrzewski, G. A. Voth, P. Salvador, J. J. Dannenberg, S. Dapprich, A. D. Daniels, O. Farkas, J. B. Foresman, J. V. Ortiz, J. Cioslowski and D. J. Fox, Gaussian 09, Revision C.01, Gaussian, Inc., Wallingford CT, 2009.

93 M. A. Rohrdanz and J. M. Herbert, J. Chem. Phys., 2008, 129, 034107.

94 A. D. Becke, J. Chem. Phys., 1993, 98, 1372-1377.

95 A. Kazaryan, J. Heuver and M. Filatov, J. Phys. Chem. A, 2008, 112, 12980-12988.

96 O. Christiansen, H. Koch and P. Jørgensen, Chem. Phys. Lett., 1995, 243, 409-418.

97 J. Conyard, K. Addison, I. A. Heisler, A. Cnossen, W. R. Browne, B. L. Feringa and S. R. Meech, Nat. Chem., 2012, 4, 547-551. 